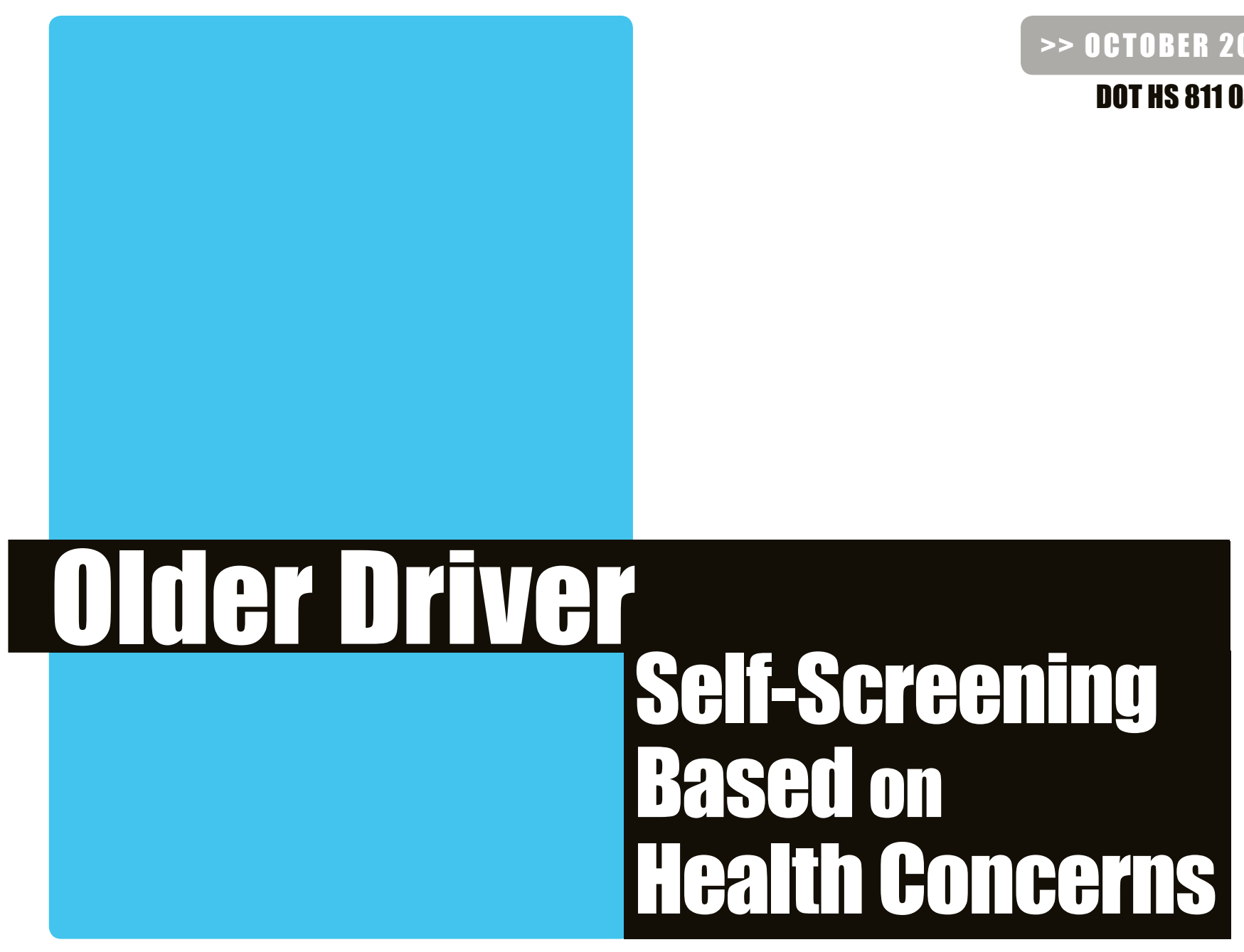

\title{
Volume l:
}

Technical Report 
This publication is distributed by the U.S. Department of Transportation, National Highway Traffic Safety Administration, in the interest of information exchange. The opinions, findings and conclusions expressed in this publication are those of the author(s) and not necessarily those of the Department of Transportation or the National Highway Traffic Safety Administration. The United States Governmentassumes no liability for its contentor use thereof. If trade or manufacturers' names or products are mentioned, it is because they are considered essential to the object of the publication and should not be construed as an endorsement. The United States Government does not endorse products or manufacturers. 
Technical Report Documentation Page

\begin{tabular}{|c|c|c|c|}
\hline $\begin{array}{l}\text { 1. Report No. } \\
\text { DOT HS } 811 \text { 046A }\end{array}$ & 2. Government Accession No. & \multicolumn{2}{|c|}{ 3. Recipient's Catalog No. } \\
\hline \multirow{2}{*}{\multicolumn{2}{|c|}{$\begin{array}{l}\text { 4. Title and Subtitle } \\
\text { Older Driver Self-Screening Based on Health Concerns } \\
\text { (Volume I: Technical Report) }\end{array}$}} & \multicolumn{2}{|c|}{$\begin{array}{l}\text { 5. Report Date } \\
\text { October } 2008\end{array}$} \\
\hline & & \multicolumn{2}{|c|}{$\begin{array}{l}\text { 6. Performing Organization } \\
\text { Code }\end{array}$} \\
\hline \multicolumn{2}{|c|}{$\begin{array}{l}\text { 7. Author(s) } \\
\text { David W. Eby, Lisa J. Molnar, Paula Kartje, Renée M. St. Louis, Julie E. } \\
\text { Parow, Jonathon M. Vivoda, \& Amy L. Neumeyer }\end{array}$} & \multicolumn{2}{|c|}{ 8. Performing Organization Report No. } \\
\hline \multirow{2}{*}{\multicolumn{2}{|c|}{$\begin{array}{l}\text { 9. Performing Organization Name and Address } \\
\text { The University of Michigan } \\
\text { Transportation Research Institute } \\
2901 \text { Baxter Road } \\
\text { Ann Arbor, Michigan 48109-2150 U.S.A. }\end{array}$}} & \multicolumn{2}{|c|}{ 10. Work Unit no. (TRAIS) } \\
\hline & & \multicolumn{2}{|c|}{$\begin{array}{l}\text { 11. Contract or Grant No. } \\
\text { DTNH22-02-D-15338 } \\
\text { Task Order } 2 \\
\end{array}$} \\
\hline \multirow{2}{*}{\multicolumn{2}{|c|}{$\begin{array}{l}\text { 12. Sponsoring Agency Name and Address } \\
\text { National Highway Traffic Safety Administration } \\
\text { Office of Behavioral Safety Research } \\
1200 \text { New Jersey Avenue SE., Washington, DC } 20590\end{array}$}} & \multicolumn{2}{|c|}{$\begin{array}{l}\text { 13. Type of Report and Period Covered } \\
\text { Final }\end{array}$} \\
\hline & & \multicolumn{2}{|c|}{ 14. Sponsoring Agenc } \\
\hline \multicolumn{4}{|c|}{$\begin{array}{l}\text { 15. Supplementary Notes } \\
\text { Jesse Blatt and Alan Block from NHTSA were the project's Task Order Managers }\end{array}$} \\
\hline \multicolumn{4}{|c|}{ 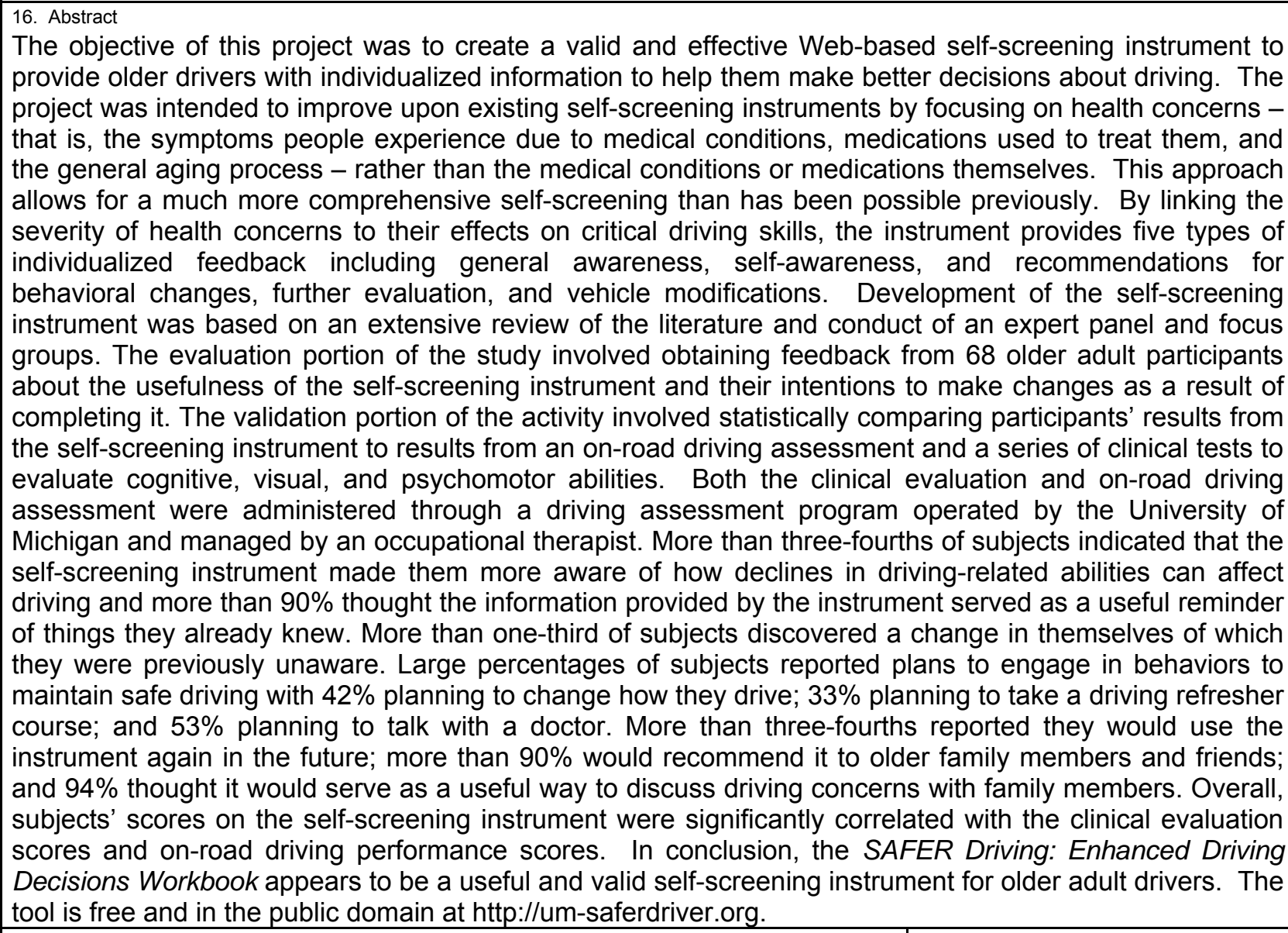 } \\
\hline \multicolumn{2}{|c|}{$\begin{array}{l}\text { 17. Key Words } \\
\text { Older Driver, Safety, Self-Screening, Decisions, Health Concerns }\end{array}$} & \multicolumn{2}{|c|}{$\begin{array}{l}\text { 18. Distribution Statement } \\
\text { Unlimited }\end{array}$} \\
\hline $\begin{array}{l}\text { 19. Security Classification (of this report) } \\
\text { Unclassified }\end{array}$ & $\begin{array}{l}\text { 20. Security Classification (of this page) } \\
\text { Unclassified }\end{array}$ & 21. No. of Pages & 22. Price \\
\hline
\end{tabular}




\section{SI* (MODERN METRIC) CONVERSION FACTORS}

APPROXIMATE CONVERSIONS TO SI UNITS

\begin{tabular}{|c|c|c|c|c|}
\hline Symbol & When You Know & Multiply By & To Find & Symbol \\
\hline \multicolumn{5}{|c|}{ LENGTH } \\
\hline in & inches & 25.4 & millimeters & $\mathrm{mm}$ \\
\hline $\mathrm{ft}$ & feet & 0.305 & meters & $\mathrm{m}$ \\
\hline yd & yards & 0.914 & meters & $\mathrm{m}$ \\
\hline $\mathrm{mi}$ & miles & 1.61 & kilometers & $\mathrm{km}$ \\
\hline \multicolumn{5}{|c|}{ AREA } \\
\hline in $^{2}$ & square inches & 645.2 & square millimeters & $\mathrm{mm}^{2}$ \\
\hline $\mathrm{ft}^{2}$ & square feet & 0.093 & square meters & $\mathrm{m}^{2}$ \\
\hline$y d^{2}$ & square yard & 0.836 & square meters & $\mathrm{m}^{2}$ \\
\hline ac & acres & 0.405 & hectares & ha \\
\hline $\mathrm{mi}^{2}$ & square miles & 2.59 & square kilometers & $\mathrm{km}^{2}$ \\
\hline \multicolumn{5}{|c|}{ VOLUME } \\
\hline floz & fluid ounces & 29.57 & milliliters & $\mathrm{mL}$ \\
\hline gal & gallons & 3.785 & liters & $\mathrm{L}$ \\
\hline $\mathrm{ft}^{3}$ & cubic feet & 0.028 & cubic meters & $\mathrm{m}^{3}$ \\
\hline $\mathrm{yd}^{3}$ & cubic yards & 0.765 & cubic meters & $\mathrm{m}^{3}$ \\
\hline \multirow{2}{*}{\multicolumn{5}{|c|}{ NOTE: volumes greater than $1000 \mathrm{~L}$ shall be shown in $\mathrm{m}^{3}$}} \\
\hline & & & & \\
\hline $\mathrm{oz}$ & ounces & 28.35 & grams & $\mathrm{g}$ \\
\hline $\mathrm{lb}$ & pounds & 0.454 & kilograms & \\
\hline $\mathrm{T}$ & short tons (2000 lb) & 0.907 & megagrams (or "metric ton") & $\mathrm{Mg}$ (or "t") \\
\hline \multicolumn{5}{|c|}{ TEMPERATURE (exact degrees) } \\
\hline${ }^{\circ} \mathrm{F}$ & Fahrenheit & $\begin{array}{r}5(\mathrm{~F}-32) / 9 \\
\text { or }(\mathrm{F}-32) / 1\end{array}$ & Celsius & ${ }^{\circ} \mathrm{C}$ \\
\hline \multicolumn{5}{|c|}{ ILLUMINATION } \\
\hline fc & foot-candles & 10.76 & lux & \\
\hline $\mathrm{fl}$ & foot-Lamberts & 3.426 & candela $/ \mathrm{m}^{2}$ & $\mathrm{~cd} / \mathrm{m}^{2}$ \\
\hline \multicolumn{5}{|c|}{ FORCE and PRESSURE or STRESS } \\
\hline lbf & poundforce & 4.45 & newtons & $\mathrm{N}$ \\
\hline $\mathrm{lbf} / \mathrm{in}^{2}$ & poundforce per square inch & 6.89 & kilopascals & $\mathrm{kPa}$ \\
\hline \multicolumn{5}{|c|}{ APPROXIMATE CONVERSIONS FROM SI UNITS } \\
\hline Symbol & When You Know & Multiply By & To Find & Symbol \\
\hline \multicolumn{5}{|c|}{ LENGTH } \\
\hline $\mathrm{mm}$ & millimeters & 0.039 & inches & in \\
\hline $\mathrm{m}$ & meters & 3.28 & feet & $\mathrm{ft}$ \\
\hline $\mathrm{m}$ & meters & 1.09 & yards & $\mathrm{yd}$ \\
\hline $\mathrm{km}$ & kilometers & 0.621 & miles & $\mathrm{mi}$ \\
\hline \multicolumn{5}{|c|}{ AREA } \\
\hline $\mathrm{mm}^{2}$ & square millimeters & 0.0016 & square inches & $\mathrm{in}^{2}$ \\
\hline $\mathrm{m}^{2}$ & square meters & 10.764 & square feet & $\mathrm{ft}^{2}$ \\
\hline $\mathrm{m}^{2}$ & square meters & 1.195 & square yards & $\mathrm{yd}^{2}$ \\
\hline ha & hectares & 2.47 & acres & $\mathrm{ac}$ \\
\hline $\mathrm{km}^{2}$ & square kilometers & 0.386 & square miles & $\mathrm{mi}^{2}$ \\
\hline \multicolumn{5}{|c|}{ VOLUME } \\
\hline $\mathrm{mL}$ & milliliters & 0.034 & fluid ounces & $\mathrm{fl} \mathrm{oz}$ \\
\hline L & liters & 0.264 & gallons & gal \\
\hline $\mathrm{m}^{3}$ & cubic meters & 35.314 & cubic feet & $\mathrm{ft}^{3}$ \\
\hline $\mathrm{m}^{3}$ & cubic meters & 1.307 & cubic yards & $\mathrm{yd}^{3}$ \\
\hline \multicolumn{5}{|c|}{ MASS } \\
\hline g & grams & 0.035 & ounces & \\
\hline $\mathrm{kg}$ & kilograms & 2.202 & pounds & $\mathrm{lb}$ \\
\hline Mg (or "t") & megagrams (or "metric ton") & 1.103 & short tons (2000 lb) & $\mathrm{T}$ \\
\hline \multicolumn{5}{|c|}{ TEMPERATURE (exact degrees) } \\
\hline${ }^{\circ} \mathrm{C}$ & Celsius & $1.8 \mathrm{C}+3$ & Fahrenheit & ${ }^{\circ} \mathrm{F}$ \\
\hline \multicolumn{5}{|c|}{ ILLUMINATION } \\
\hline $1 \mathrm{x} d / \mathrm{m}^{2}$ & $\operatorname{lux}$ & 0.0929 & foot-candles & fc \\
\hline \multirow{2}{*}{\multicolumn{5}{|c|}{ FORCE and PRESSURE or STRESS }} \\
\hline $\mathrm{N}$ & & & & \\
\hline $\mathrm{kPa}$ & kilopascals & 0.145 & poundforce per square inch & $\mathrm{lb} f / \mathrm{in}^{2}$ \\
\hline
\end{tabular}

*SI is the symbol for the International System of Units. Appropriate rounding should be made to comply with Section 4 of ASTM E380. (Revised March 2003) 


\section{CONTENTS}

INTRODUCTION
METHODS.
Literature Review
Expert Panel
Self-Screening Instrument Development
Evaluation/Validation Study
Participant Recruitment
Study Protocols
Data Analysis
Self Awareness and Usefulness
Validation
DISCUSSION.
REFERENCES




\section{ACKNOWLEDGMENTS}

We are grateful to several individuals who contributed to this project. Dr. Jesse Blatt, formerly of the National Highway Traffic Safety Administration (NHTSA), had the vision to base self-screening on health concerns. This project is based greatly on his ideas. Alan Block was the NHTSA Task Order Manager and provided valuable feedback. Drs. David Carr, Anne E. Dickerson, Bonnie M. Dobbs, Allen R. Dobbs, Richard A. Marottoli, Dennis P. McCarthy, Germaine Odenheimer, Nina M. Silverstein, Jane Stutts, Leonard Trujillo, and Ms. Essie Wagner generously provided their expertise to the project. Adam Nation, Linda Miller, and Judy Settles, all from UMTRI, assisted in conducting the project. Chris DiVirgilio of UMTRI developed the Web site code.

The content, evaluation, and validation of um-saferdriving.org were developed through the support of the United States Department of Transportation (U.S. DOT) NHTSA under contract number DTNH22-02-D-15338 (Task Order \#2). Web site development was sponsored by the University of Michigan Transportation Research Institute (UMTRI). The tool is free and in the public domain. The opinions, findings, and conclusions are those of the authors and not necessarily those of the U.S. DOT or NHTSA. 


\section{INTRODUCTION}

The issue of older driver safety continues to be an important research topic despite having received increased attention over the past decade. It is clear that people are living longer than in the past. In the United States, the proportion of people age 65 and older has grown from less than $10 \%$ in 1950 to about $13 \%$. By 2030, the percentage of the U.S. population over 65 is projected to reach nearly $20 \%$ (U.S. Census Bureau, 2006). In terms of absolute numbers, those over age 65 will increase from about 35 million currently to about 70 million in 30 years (U.S. Department of Commerce, 2001). As described by Hakamies-Blomqvist (2004), it is less clear whether older drivers are at a higher risk of crash than younger drivers. The basis of this issue is that the typical measures of exposure (population, licensed drivers, and vehicle miles traveled) are either potentially biased or are difficult to determine accurately. Nonetheless, there is strong evidence that for a crash of given dimensions, an older driver is more likely to be injured than a younger driver, due, presumably, to increased frailty (see e.g., Evans, 1991; Massie \& Campbell, 1993). As such, older drivers are likely to be more highly represented in fatal and serious crashes (Hauer, 1988; Maycock, 1997).

Older drivers as a group tend to be involved in different types of crashes than younger drivers. For example, when compared with younger drivers, drivers over age 65, and particularly drivers over age 75 , have more vehicle-to-vehicle collisions, more intersection crashes, and fewer alcohol-involved crashes (e.g., Dulisse, 1997; Eby, 1995; Hakamies-Blomqvist, 1994, 2004; Hauer, 1988). Such findings are in line with what is known about driver behavior in this age group. Older drivers as a group adjust their driving to reduce the demands of the driving task (Gallo, Rebok, \& Lesiker, 1999; Kostyniuk, Shope, \& Molnar, 2000); that is, older drivers tend to travel slower and choose times, roadways, and routes that make them feel safest. Unlike crashes among younger drivers, older-driver crashes appear to result, not from deliberate risk-taking and immaturity, but rather from age-related declines in driving abilities (Staplin, Gish, Decina, Lococo, \& McKnight, 1998).

It is well-established that aging can lead to declines in perceptual, cognitive, and psychomotor function (see Eby, Trombley, Molnar, \& Shope, 1998 for a review). These declines result from age-related medical conditions and the medications used to treat them, as well as from the effects that increasing age has on the various systems of the human body. Accurately assessing declines in driving abilities and relating them to increased crash risk has been a goal of traffic safety professionals for many years. While this research slowly progresses, the self-screening of driving ability has shown promise (Eby et al., 2003). As described by Eby et al. (2003), there are several benefits of self-screening: reluctant drivers may be more willing to self-assess than to be professionally assessed; people may discover declines at an earlier stage; and selfscreening instruments can reach a wide variety of people because such instruments are easily distributed.

Several self-screening instruments are available for older drivers, including Drivers 55 Plus (AAA Foundation for Traffic Safety, 1994), the AAA Roadwise Review, and the Driving Decisions Workbook (Eby et al., 2003). Each of these instruments takes a different approach to self-screening and covers different areas. Drivers 55 Plus uses a 
different approach to self-screening and covers different areas. Drivers 55 Plus uses a questionnaire format to come up with a composite score of driving ability over a small number of topics. The AAA Roadwise Review is an interactive CD-ROM instrument based on the clinical DrivingHealth Inventory program (see Staplin \& Lococo, 2003). No published evaluation results are available for AAA Roadwise Review, but AAA reports that users enjoy the program and state their intent to follow the recommendations provided. The Driving Decisions Workbook uses a questionnaire format like Driver 55 Plus, but covers a much wider range of topics, including diagnoses of medical conditions and medication use. In addition, the Driving Decisions Workbook gives users individualized feedback based on how they answer questions.

Preliminary evaluation of the Driving Decisions Workbook showed that outcomes of the instrument, when examined overall, were correlated with observed problems with actual driving on a standardized road test and that users liked the instrument, learned from it, and reported intentions to adopt safe driving practices as a result of completing it (Eby et al., 2003). However, when scores on just the health section of the workbook, which included medical conditions and medication use, were compared with observed driving problems, no significant correlation was found. In retrospect, such a result is not surprising. As discussed in a recent expert panel on older driver polypharmacy, the interaction between medical conditions, the drugs used to treat them, and their combined influence on driving skills is complex (Wilkinson \& Moskowitz, 2001). A properly treated medical condition may not produce any change in driving ability, and the side effects of certain medications may not adversely affect driving except under certain circumstances. Thus, a diagnosis of a certain medical condition, or treatment with a certain medication, will not necessarily adversely affect driving as is assumed in the Driving Decisions Workbook. Developing a self-screening instrument in a questionnaire format that covered each medical diagnosis under multiple treatment conditions and driving circumstances would be a monumental task that would yield an instrument too large to be useful.

The purpose of this project was to improve upon existing self-screening instruments by focusing entirely on health concerns that affect driving - that is, the symptoms that people experience due to medical conditions, the medications used to treat them, and the general aging process - rather than the medical conditions or medications themselves. The development of the self-screening instrument was based on the assumption that while there are a myriad of medical conditions, medications, and agerelated declines, they produce a relatively small number of health concerns that can vary in severity, and in turn affect driving. Thus, it should be possible to self-assess the severity of these concerns and give drivers specific feedback about how health-concern severity affects driving and what can be done to continue driving safely.

The project's objective was to create an easy-to-use self-screening instrument for older drivers that would provide several types of individualized feedback including information to increase general awareness and self-awareness relative to declines in driving-related abilities, as well as recommendations for behavioral changes or safety tips to maintain safe driving (e.g., avoiding driving at night, taking a driver refresher course, planning a trip in advance and writing down the route), further evaluation from a physician or other health professional, and vehicle modifications to help compensate for driving-related declines. Project activities included an extensive literature review, convening an expert panel to discuss how health-concern severity relates to driving skills and to identify 
appropriate accommodations for declines in these skills, preliminary development of a Web-based self-screening instrument guided by focus group input from older drivers, and an evaluation/validation study using a geriatric driver assessment professional. This technical report contains summary information about the activities conducted as part of this project. Fuller detail on these activities can be found in the appendices contained in Volume II (Eby, Molnar, Kartje, St. Louis, Parow, Vivoda, \& Neumeyer, 2007). 


\section{METHODS}

\section{Literature Review}

The literature review had two parts. The focus of the first part was to better understand the health concerns that might influence driving. The objective was to develop a list of health concerns and to estimate the severity of these concerns and the conditions under which each concern would be most likely to occur. The focus of the second part of the literature review was to identify critical driving skills (those skills most critical for driving safely under the conditions most common to older adult driving) and to determine what capabilities would be required to perform each skill adequately.

Both parts of the literature review were conducted as follows. Search criteria were developed from two previous literature reviews on driving and aging conducted by the principal investigators (Eby et al., 1998; Molnar, Eby, \& Miller, 2003), from the project team's knowledge of the literature on aging, and from discussions with the NHTSA Task Order Manager. These search criteria were used to gather appropriate articles, reports, and other documents. The following databases were searched: MEDLINE, PSYCINFO, TRISonline, ProQuest, ScienceDirect, and UM-MIRLYN. Documents were also gathered from the UMTRI library which houses many transportation-related documents that have not been published. Collected articles were reviewed by project staff and appropriate articles were referenced in an annotated bibliography that contains, for each article, the document citation, a brief summary of the original purpose of the document, and a summary of the relevant content. This bibliography can be found in Volume II, Appendix A.

\section{Expert Panel}

A panel of subject matter experts was convened to (1) help finalize the lists of appropriate health concerns and critical driving skills to be included in the self-screening instrument; (2) discuss how severity levels of the health concerns influence critical driving skills; and (3) consider the content of the self-screening instrument's feedback relative to recommendations for behavioral changes, further evaluation, and vehicle modifications. Panel members were selected from a variety of backgrounds with expertise in geriatrics, driving task analysis, highway safety, and vehicle modifications. The participants and their affiliations were:

Jesse Blatt, Ph.D. (Task Order Manager)

Senior Research Psychologist

National Highway Traffic Safety Administration

Washington, DC

Essie Wagner, M.A.

Program Analyst

National Highway Traffic Safety Administration

Washington, DC

David W. Eby, Ph.D. (Principal Investigator)

Research Associate Professor and Head

Social and Behavioral Analysis

University of Michigan Transportation Research Institute 
Ann Arbor, MI

Lisa J. Molnar, M.H.S.A. (Co-investigator)

Senior Research Associate

Social and Behavioral Analysis

University of Michigan Transportation Research Institute

Ann Arbor, MI

Paula Kartje, OTR, CDRS (Co-investigator)

Manager

University of Michigan Health System

MedRehab Occupational Therapy and Drive-Ability Program

Ann Arbor, MI

Anne E. Dickerson, Ph.D., OTR/L, FAOTA

Professor and Chair, Department of Occupational Therapy

East Carolina University

Greenville, NC

Bonnie M. Dobbs, Ph.D.

Associate Director, Rehabilitation Research Centre

Associate Professor, Faculty, Rehabilitation Medicine

University of Alberta

Edmonton, Alberta

Allen R. Dobbs, Ph.D.

President and CEO, DriveABLE Assessment Centres, Inc.

Edmonton, Alberta

Richard A. Marottoli, M.D., M.P.H.

Associate Professor of Medicine

Director, VAMC Section of Geriatrics and Extended Care

Co-Director, Integrated Model of Aging and Geriatric Education

West Haven, CT

Dennis P. McCarthy, MED, OTR/L

Co-Director, National Older Driver Research and Training Center

University of Florida

Gainesville, FL

Linda L. Miller, B.A.

Research Assistant

Social and Behavioral Analysis

University of Michigan Transportation Research Institute

Ann Arbor, MI

Jean T. Shope, M.S.P.H., Ph.D.

Research Professor

Social and Behavioral Analysis

University of Michigan Transportation Research Institute 
Ann Arbor, MI

Nina M. Silverstein, Ph.D.

Associate Professor of Gerontology

Gerontology Institute

University of Massachusetts

Boston, MA

Jane Stutts, Ph.D.

Associate Director for Social and Behavioral Research

University of North Carolina Highway Safety Research Center

Chapel Hill, NC

\section{Leonard Trujillo, Ph.D.}

Department of Occupational Therapy

East Carolina University

Greenville, NC

Prior to the meeting, all panel members were mailed a packet of information that included a description of the project, the preliminary lists of health concerns and critical driving skills, and worksheets for linking health concerns and critical driving skills (see Volume II, Appendix B). Participants were instructed to complete the worksheet and provide any additional feedback prior to the panel meeting.

The two-day panel meeting was held September 8-9, 2005, at the University of Michigan in Ann Arbor. As shown in Volume II, Appendix C, the meeting began with a welcome and introductions. Panel members then discussed the list of health concerns and the list of critical driving skills. This discussion centered on which concerns and skills should appropriately be included in the self-screening instrument. Once consensus was reached, the group split into four subgroups to discuss the severity level at which each health concern might affect driving safety. Each group was given a different set of health concerns to discuss. The panel then reconvened and results from each subgroup were reported. For the remainder of the first day, the subgroups discussed how each health concern might influence critical driving skills. The second day began with each subgroup reporting on the linkages followed by discussion. The panel ended with a discussion of specific recommendations that could be provided as feedback for the self-screening instrument, including recommendations for behavioral changes, further evaluation, and vehicle modifications.

After the meeting, the researchers synthesized the meeting results into a series of PowerPoint slides showing how the panel decided the health concerns were linked to critical driving skills at three levels of condition severity. Based on feedback from panel members, the PowerPoint slides were revised (see Volume II, Appendix D).

The final list of health concerns can be found in Table 1 and the final list of critical driving skills can be found in Table 2 .

Table 1: List of Health Concerns Used in the Self-Screening Instrument 


\begin{tabular}{|l|l|}
\hline \multicolumn{1}{|c|}{ Health Concern } & Health Concern \\
\hline Reduced Visual Acuity & Depression \\
\hline Increased Sensitivity to Glare & Drowsiness/Sleepiness \\
\hline Reduced Peripheral Vision & Pain \\
\hline Reduced Contrast Sensitivity & Anxiety \\
\hline Poor Depth Perception & Cognitive Inflexibility \\
\hline Visual Scanning Deficits & Impulsiveness \\
\hline Visuospatial Deficits & Upper Body Stiffness \\
\hline Divided Attention Deficits & Upper Body Weakness \\
\hline Selected Attention Deficits & Slowed Physical Movements \\
\hline Slowed Information Processing & Endurance \\
\hline Forgetfulness & Neuropathy \\
\hline Getting Lost & Impaired Coordination \\
\hline Confusion & Tremors \\
\hline Difficulty Following Directions & \\
\hline
\end{tabular}

\begin{tabular}{|c|l|}
\hline \multicolumn{2}{|c|}{ Table 2: Final List Of Critical Driving Skills and Definitions Used in the Self- } \\
Screening Instrument
\end{tabular}




\begin{tabular}{|c|c|}
\hline & $\begin{array}{l}\text { is determined both by the distance between vehicles and the speed they are } \\
\text { traveling. Research shows that many crashes are caused by drivers inappropriately } \\
\text { judging a gap length. }\end{array}$ \\
\hline Speed & $\begin{array}{l}\text { The appropriate driving speed is based on the posted speed limit and the conditions } \\
\text { of the roadway. Speeds should be reduced, for example, if the road is slippery. } \\
\text { Note that traffic crashes can be caused by drivers traveling too fast and by drivers } \\
\text { traveling too slow. }\end{array}$ \\
\hline Backing Up & $\begin{array}{l}\text { Backing up is an important driving skill because it is difficult to see what is behind } \\
\text { your car, and it can be hard to steer while traveling in reverse. This skill involves } \\
\text { being able to use mirrors and being able to turn your neck and body to see what is } \\
\text { behind the vehicle. }\end{array}$ \\
\hline $\begin{array}{l}\text { Maintaining Proper } \\
\text { Lane Position }\end{array}$ & $\begin{array}{l}\text { The lines on the road are designed to show drivers where cars should be driven. } \\
\text { Exceeding these lines can lead to traffic crashes. Proper lane position is important } \\
\text { not only while traveling in a traffic lane but also while negotiating intersections. }\end{array}$ \\
\hline Following & $\begin{array}{l}\text { Maintaining a proper following distance behind the vehicle in front of you is } \\
\text { important for the prevention of rear-end crashes. The proper following distance is } \\
\text { determined by the distance between you and the next vehicle, as well as the speed } \\
\text { at which you are traveling. With greater travel speeds, a larger distance between } \\
\text { vehicles is needed for safe following. }\end{array}$ \\
\hline Signaling & $\begin{array}{l}\text { Signaling your intent to turn or change lanes is important for safe driving because it } \\
\text { lets other drivers and pedestrians know what you are about to do. It is equally } \\
\text { important to remember to turn off the signal after you turn or change lanes so that } \\
\text { others know you are done. }\end{array}$ \\
\hline Use of Headlights & $\begin{array}{l}\text { Headlights are important for being able to see while driving at night and during bad } \\
\text { weather. They are also important for letting other drivers and pedestrians know } \\
\text { where you are when seeing is difficult. Remembering to turn off the bright "high- } \\
\text { beam" for approaching vehicles is also important for safe driving because high- } \\
\text { beam lights can make seeing difficult for the other driver. }\end{array}$ \\
\hline
\end{tabular}

\section{Self-Screening Instrument Development}

Development of the self-screening instrument involved five tasks. The first was a series of brainstorming sessions with the project team members. These sessions focused mainly on comparing the merits of a paper-and-pencil instrument versus an electronic instrument with respect to format, feedback, accessibility/ease of use, dissemination, and ease of updating. Regardless of the interface mode, team members agreed that the instrument would be in a questionnaire format; that is, people would answer questions about each health concern and indicate the level of severity they were experiencing (from none to severe). These responses would then be used to determine the appropriate feedback on behavioral changes, further evaluation, and vehicle modifications. Team members decided that an electronic (Web site) format was superior to a paper-and-pencil instrument because the electronic interface would allow greater control over tailoring feedback that was both individual and non-repetitive. The electronic format would also allow the instrument to use an algorithm to convert the severity scores into appropriate feedback. While many older adults may not have easy access to the Internet or be comfortable using computers, the team felt that as long as the Web page was clear and easy to negotiate, many older adults would use the Web site. In terms of dissemination, the self-screening instrument would be available to a world-wide English-speaking audience at no cost. In addition, as research moves forward, the Web site could be more easily updated than printed media. The final outcome of the brainstorming session was the selection of a name for the self-screening instrument: SAFER Driving: Enhanced Driving Decisions Workbook (standing for SelfAwareness and FEedback for Responsible Driving).

The second task involved a set of focus groups with drivers age 65 and older conducted prior to instrument development to assess the groups' reaction to potential Web site 
issues and features. Volume II, Appendix E contains the moderator's guide and a summary of the focus group results.

The third task involved developing the draft Web site for the SAFER Driving instrument. Based on previous project activities, 27 health concerns (13 cognitive, 10 motor, 7 visual) and 15 critical driving skills were chosen for inclusion in the instrument. For each health concern, a set of three to five questions was chosen from a larger set of validated self-report questionnaire items identified through the literature review.

Each health concern was then linked (based on expert opinion) to the driving skills at low, medium, and high levels of severity, depending on the concern. This is shown graphically in Figure 1.

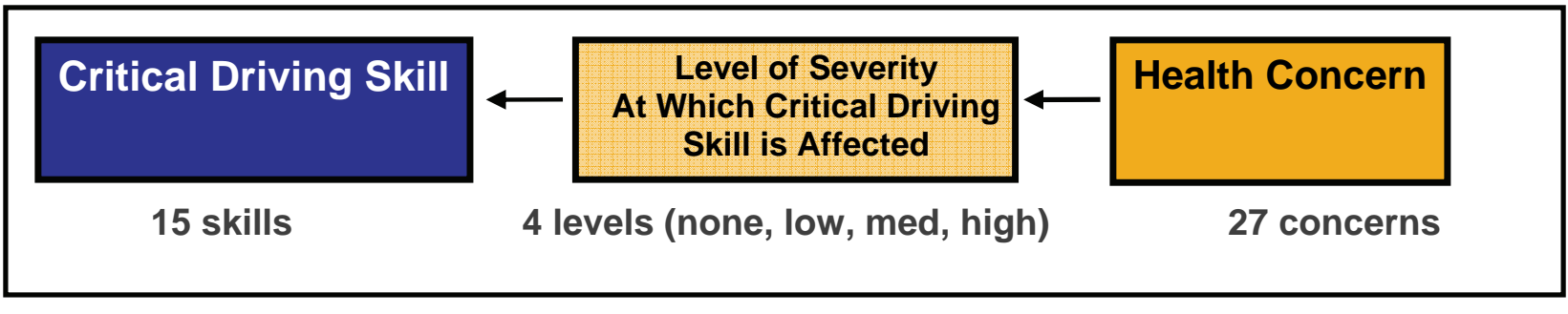

Figure 1: Conceptual model of SAFER Driving instrument

The following steps and logic were developed for linking health concerns to critical driving skills and selecting individualized feedback for the SAFER Driving Web site.

Step 1: Assess level of severity experienced by user of self-screening instrument for each health concern.

- The question responses are mapped to one of the four levels of severity based on how the questions are answered.

- Questions have either two (no, yes) or five (none, a little, some, a lot, extreme; never, rarely, sometimes, often, always) response categories. The dichotomous questions are coded as follows:

o For each question: No $\rightarrow$ none (0); Yes $\rightarrow$ Low (1);

The five-category responses are recoded into four categories as follows:

o None and a little $\rightarrow$ none (0); some $\rightarrow$ low (1); a lot $\rightarrow$ med (2); extreme $\rightarrow$ high (3);

o Never and rarely $\rightarrow$ none (0); sometimes $\rightarrow$ low (1); often $\rightarrow$ med (2); always $\rightarrow$ high (3).

- Each health concern is measured by three to five questions.

- Severity level is determined by modal response; if there is no distinct mode, then the median is used.

Step 2: Determine which critical driving skills are affected by user's health concerns.

- The mappings from health concern severity level to effect on critical driving skill was determined by an expert panel.

- For example, based on the mappings from the expert panel, the health concern "anxiety" affects the following critical driving skills at the specified levels of severity: 
o None: no skills are affected;

o Low: pre-trip, way finding, yielding, turning, speed control, signals, backing, changing lanes, passing; and gap acceptance;

o Medium: pre-trip, way finding, yielding, turning, speed control, signals, backing, changing lanes, passing; gap acceptance, lane position, and following;

o High: pre-trip, way finding, yielding, turning, speed control, signals, backing, changing lanes, passing; gap acceptance, lane position, following, signaling, and headlight use.

Step 3: Calculate overall score and three sub-scores for each critical driving skill.

These scores, along with a threshold $(\geq 25 \%)$, determine whether a person gets feedback on that critical driving skill.

Step 4: Determine the set of health concerns for which the person will get feedback.

- Whether or not a person gets feedback on a specific health concern depends on the mappings in step 3.

- Any health concern that leads to a mapping in which a person receives feedback on a critical driving skill is included in the individualized feedback.

o For example, if the person's responses indicate that they have a low level of the "anxiety" health concern and this severity level mapped to potential problems with at least one critical driving skill, then the health concern "anxiety" was included in the feedback list of potential health concerns the person is experiencing.

Step 5: Provide individualized feedback.

- Individualized lists of potential health concerns, potential critical driving skills affected, and tips for safer mobility given these health concerns and potential driving problems are prepared and presented to the respondent.

- The health concerns and critical driving skills can be clicked-on to receive further information.

- The feedback can be printed in a printer-friendly format and the feedback can be saved for later viewing.

After the Web site logic was developed, a Web programmer was hired to develop the code. The project team worked closely with the programmer on format and style of the Web site. A Web site domain name was purchased in order to improve access to the site (UM-SAFERdriving.org).

The fourth activity was to develop the actual feedback that would be provided to users based on their individual responses to the questions in the self-screening instrument (using the logic described in Steps 1-5 above), with separate feedback presented for each health concern and each critical driving skill identified. For example, if "reduced visual acuity" and "increased sensitivity to glare" were the only health concerns identified for a particular subject, then he or she would be provided with feedback only on those two health concerns and not other health concerns. However, a full set of feedback needed to be developed and available in the self-screening instrument. Feedback on health concerns included a brief description of each concern and what it might mean for safe driving, as well as recommendations (when appropriate) for behavioral changes and safety tips, follow-up by a professional, and vehicle modifications. Feedback on critical driving skills included a brief description of each skill and how it relates to safe driving. Feedback was written by the project team based on the literature review and results from the expert panel. 
The final activity was to present and discuss the SAFER Driving instrument in a focus group with drivers age 65 and older. The purposes of the group discussion were to ensure that the questions and feedback were appropriate and understandable, to gather feedback on the Web site format and style, and to determine how users would interact with the Web site. The moderator's guide and summary of this focus group can be found in Volume II, Appendix F. The SAFER Driving instrument was revised based on this feedback. The final version of the SAFER Driving: Enhanced Driving Decisions Workbook can be found at www.um-saferdriving.org. The tool is free to use and is in the public domain.

\section{Evaluation/Validation Study}

The purpose of this part of the project was to evaluate and validate the self-screening instrument developed from the five activities listed above, using a sample of 68 older adult drivers in Southeastern Michigan. The evaluation portion of the study was intended to assess whether the instrument increased self-awareness of age-related declines in driving abilities and whether it was perceived as useful. It involved obtaining feedback from participants after they had completed the self-screening instrument relative to their understanding of the instrument, their ability to follow directions, and their intentions to change their driving as a result of completing the instrument, as well as the perceived usefulness of the instrument in general, and the perceived usefulness of the instrument for facilitating discussions between older drivers and their families about the former's driving concerns.

The validation portion of the activity was intended to assess the extent to which the instrument accurately identified health concerns and potential driving difficulties. It involved comparing the participants' results from the self-screening instrument to their results from an on-road driving assessment and a series of clinical tests (pencil/paper and other non-invasive) that evaluated cognitive, visual, and psychomotor abilities related to driving. Both the clinical evaluation and the on-road driving assessment were administered through an established driving assessment program operated by the University of Michigan (UM Drive-Ability Program) and managed by an occupational therapist who was also a member of the project team. Further details about these activities are provided below.

\section{Participant Recruitment}

Participants for the study were recruited in two ways. Ten participants were recruited from a pool of medical patients referred to the UM Drive-Ability program by their physicians for a comprehensive driving assessment (see Volume II, Appendix G for recruitment letter to referring physicians). The remaining 58 participants were recruited from postings at senior centers, medical facilities, and other organizations frequented by older adults in Washtenaw County, Michigan, as well as from lists of past participants in research at UMTRI (see Volume II, Appendix $\mathrm{H}$ for recruitment posting). Eligibility criteria for inclusion in the study included being age 65 or older, having a valid driver's license, having the cognitive skills necessary to complete the various assessments as determined by the judgment of a telephone screener, and being available to complete a 3-3.5 hour appointment for testing at the Drive-Ability Program. To determine eligibility for study participation and to gather background information on potential study participants, a telephone screening tool was developed and used (see Volume II, Appendix I). The demographic characteristics of study subjects are shown in Table 3. 


\begin{tabular}{|c|c|c|}
\hline \multicolumn{3}{|c|}{ Table 3: Subject Demographics } \\
\hline & Number & Percent \\
\hline $\begin{array}{l}\text { Sex } \\
\quad \text { Male } \\
\text { Female }\end{array}$ & $\begin{array}{l}34 \\
34\end{array}$ & $\begin{array}{l}50.0 \\
50.0\end{array}$ \\
\hline $\begin{array}{c}\text { Age } \\
65-74 \\
75+\end{array}$ & $\begin{array}{l}34 \\
34\end{array}$ & $\begin{array}{l}50.0 \\
50.0\end{array}$ \\
\hline $\begin{array}{l}\text { Education } \\
\text { High School or Less } \\
\text { Some College or Trade School } \\
\text { College Graduate or Higher }\end{array}$ & $\begin{array}{r}6 \\
5 \\
57\end{array}$ & $\begin{array}{r}8.9 \\
7.3 \\
83.8\end{array}$ \\
\hline $\begin{array}{l}\text { Race } \\
\text { White/Caucasian } \\
\text { African-American/Black } \\
\text { Asian } \\
\text { Other }\end{array}$ & $\begin{array}{r}62 \\
1 \\
3 \\
2\end{array}$ & $\begin{array}{r}91.2 \\
1.5 \\
4.4 \\
2.9\end{array}$ \\
\hline $\begin{array}{l}\text { Ethnicity } \\
\text { Hispanic } \\
\text { Non-Hispanic } \\
\text { Not Reported }\end{array}$ & $\begin{array}{r}1 \\
64 \\
3\end{array}$ & $\begin{array}{r}1.5 \\
94.1 \\
4.4\end{array}$ \\
\hline $\begin{array}{l}\text { Household Income } \\
\text { Less than } \$ 20,000 \\
\$ 20,000-\$ 49,000 \\
\$ 50,000-\$ 79,000 \\
\$ 80,000-\$ 99,999 \\
\$ 100,000 \text { or more } \\
\text { Not Reported }\end{array}$ & $\begin{array}{r}5 \\
14 \\
19 \\
9 \\
11 \\
10\end{array}$ & $\begin{array}{r}7.4 \\
20.6 \\
27.9 \\
13.2 \\
16.2 \\
14.7\end{array}$ \\
\hline $\begin{array}{l}\text { Marital Status } \\
\text { Single } \\
\text { Married } \\
\text { Divorced } \\
\text { Widow(er) }\end{array}$ & $\begin{array}{r}4 \\
47 \\
5 \\
12\end{array}$ & $\begin{array}{r}5.9 \\
69.1 \\
7.4 \\
17.7\end{array}$ \\
\hline $\begin{array}{l}\text { Miles Driven per Week } \\
10 \text { or less } \\
11 \text { to } 30 \\
31 \text { to } 50 \\
51 \text { to } 100 \\
\text { More than } 100 \\
\end{array}$ & $\begin{array}{r}3 \\
17 \\
17 \\
13 \\
18\end{array}$ & $\begin{array}{r}4.4 \\
25.0 \\
25.0 \\
19.1 \\
26.5\end{array}$ \\
\hline
\end{tabular}




\section{Study Protocols}

Upon arriving at the UM Drive-Ability Program, participants completed a number of activities. First, each participant read and signed a University of Michigan Institutional Review Board informed consent document for participation in the study. Second, each participant was introduced to the Web-based self-screening instrument, which he or she completed independently if able, or with assistance from project staff if necessary. After completing the self-screening instrument, each participant received a printed copy of his or her personalized feedback to take home. Third, each participant provided feedback about the general usefulness and other dimensions of the self-screening instrument (see Volume II, Appendix J). Fourth, each participant completed a clinical evaluation administered by an occupational therapist who was a certified driving rehabilitation specialist. The evaluation included the following components:

- Medical and driving history

- Vision

- Perception

- Physical abilities

- Cognitive skills

- Driving knowledge

Results of the evaluation were recorded, and a copy of the results was given to the study participant (see Volume II, Appendix K for Clinical Evaluation Form). Finally, each study participant completed an on-road driving assessment conducted by a certified driving instructor/occupational therapist, separate from the specialist who administered the clinical evaluation. The on-road course consisted of several types of roadways in the Ann Arbor, Michigan, area (e.g., parking lot, residential, two-lane to five-lane roadways, divided highways, expressways) and took about 45 minutes to complete. The on-road assessment was completed in a dual-controlled vehicle, with participants oriented to the equipment in the vehicle prior to beginning the assessment. Each participant was scored on 25 distinct driving maneuvers or actions (see Volume II, Appendix $L$ ). After completing the on-road assessment, each participant was provided with a copy of the results, as well as feedback on driving skills observed during the assessment and recommendations for improving driving in areas considered to be problematic.

For study participants who had been recruited via physician referral to the UM DriveAbility program, results of the comprehensive driving assessment were provided to the referring physician as they normally would have been in the absence of the study. All study participants, regardless of how they had been recruited, received copies of feedback from the self-screening instrument, as well as results of the clinical evaluation and on-road assessment.

\section{Data Analysis}

To determine whether responses on the self-screening instrument that indicated potential problems with driving were correlated with observed problems during actual driving, and with deficits in driving-related abilities identified during the clinical evaluation, scores from the instrument were compared with scores from the on-road test 
and clinical evaluation. All scores for all measures were normalized to range between 0 and 100.

An overall score for the self-screening instrument was derived by adding up, for each study participant, the total number of the $\mathbf{2 7}$ health concerns identified for him or her, based on responses to the questions about each concern (see earlier discussion of logic for mapping instrument responses to health concern feedback). This score was then divided by 27 and multiplied by 100 . The range of scores resulting from participants in the study was $0-44.4$, with higher scores indicating more health concerns identified.

A composite score was also developed for the on-road driving assessment, based on how participants performed on each of 25 driving maneuvers included in the course (e.g., pre-ignition, back out of parking space, turn right). For each maneuver, participants could receive a score of 1-5 with 1 being the poorest and 5 the best performance. This score was then divided by 125 and multiplied by 100 to normalize the scale as with the other measures. The scores for participants ranged from $28.8-100$, with higher scores indicating better driving performance.

The composite score for the clinical evaluation was derived by normalizing each of the 34 individual subtests of the clinical evaluation so that each score ranged between 0 and 100, with higher scores indicating poorer clinical function. The overall score for a subject was derived by taking the average of these individual scores. These tests measured vision (e.g., visual acuity, depth perception, peripheral fields), cognition (e.g., attention, memory, reasoning/problem solving), and psychomotor skills (e.g., endurance, upper and lower extremity strength and coordination). Scores for participants in the sample ranged from 5.9 to 35.4, with higher scores indicating poorer functioning.

Data from all of the data collection forms were entered into an electronic format and checked for errors. Data were analyzed using the SAS Statistical Software package. Validation of the self-screening instrument involved statistically comparing participants' results from the self-screening instrument to results from the on-road driving assessment and clinical evaluation, using Spearman correlations.

\section{RESULTS}

As described previously, the evaluation/validation portion of the study had two purposes: (1) to determine if the instrument increased self-awareness of age-related declines in driving abilities and was perceived as useful; and (2) to determine the extent to which the instrument accurately identified health concerns and potential driving difficulties.

\section{Self-Awareness and Usefulness}

Feedback from subjects about the self-screening instrument was obtained through 11 items designed to assess whether the instrument increased self-awareness, led to intentions to engage in safety-related behavioral changes, and was perceived as useful. Responses are summarized in Table 4. The first three items addressed self- 
awareness. About three-quarters of subjects thought the self-screening instrument made them more aware of changes that can affect driving, more than 90 percent thought it served as a useful reminder of things they already knew, and more than onethird discovered changes in themselves of which they were previously unaware. This latter finding is especially interesting given that all but 10 of the subjects were healthy volunteers who came into the study knowing that their driving ability was being evaluated.

Four items addressed intentions to make various changes as a result of completing the instrument. More than 40 percent of subjects indicated that after completing the selfscreening instrument, they were going to make changes in the way they drove and onethird of subjects indicated that they were now thinking about taking a driving refresher course. More than one-half of subjects indicated that they were now more likely to discuss health concerns they were experiencing with a doctor. Few subjects, however, reported considering vehicle modifications.

The remaining items addressed the usefulness of the self-screening instrument. A vast majority of subjects responded positively: more than three-quarters of subjects indicated that they would use the Web-based instrument again in the future, more than $90 \%$ would recommend it to older friends and family members, and nearly $94 \%$ thought it would help older adults talk about driving concerns with their families. Overall, more than one-third of subjects thought the instrument was extremely useful and close to $50 \%$ indicated that it was moderately useful. Fisher's exact analyses were conducted to test for differences by sex and age for each statement. While there appear to be clear differences, these were not statistically significant.

\begin{tabular}{|l|r|r|r|r|r|}
\hline \multicolumn{7}{|c|}{ Table 4: Percent of Respondents Agreeing With Statements } \\
\hline & \multicolumn{1}{|c|}{ Overall } & \multicolumn{1}{|c|}{ Men } & Women & $\begin{array}{c}\text { Age } \\
\text { 65-74 }\end{array}$ & Age 75+ \\
\hline $\begin{array}{l}\text { The workbook made me more aware of } \\
\text { changes that can affect driving. }\end{array}$ & 76.2 & 72.7 & 80.0 & 81.3 & 71.0 \\
\hline $\begin{array}{l}\text { I discovered changes in myself that I } \\
\text { had not been aware of before. }\end{array}$ & 37.7 & 34.4 & 41.3 & 40.6 & 34.5 \\
\hline $\begin{array}{l}\text { The feedback served as a useful } \\
\text { reminder of things I already knew. }\end{array}$ & 93.8 & 94.0 & 93.5 & 93.9 & 93.5 \\
\hline $\begin{array}{l}\text { As a result of the workbook, I plan to } \\
\text { make changes in the way I drive. }\end{array}$ & 41.9 & 37.5 & 46.6 & 50.1 & 33.4 \\
\hline $\begin{array}{l}\text { As a result of the workbook, I plan to } \\
\text { consider modifying my vehicle. }\end{array}$ & 11.3 & 9.1 & 13.8 & 12.5 & 10.0 \\
\hline $\begin{array}{l}\text { I am thinking about taking a driving } \\
\text { refresher course or how a course might } \\
\text { benefit me. }\end{array}$ & 33.3 & 25.1 & 42.0 & 39.4 & 26.6 \\
\hline $\begin{array}{l}\text { I am now more likely to discuss health } \\
\text { concerns I am experiencing with my } \\
\text { doctor. }\end{array}$ & 52.5 & 48.5 & 56.6 & 51.5 & 53.3 \\
\hline $\begin{array}{l}\text { If available, I would be likely to use the } \\
\text { workbook in the future. }\end{array}$ & 76.6 & 69.7 & 83.9 & 72.8 & 80.7 \\
\hline $\begin{array}{l}\text { I would recommend the workbook to } \\
\text { lder adult friends or family members. }\end{array}$ & 92.2 & 87.9 & 96.8 & 93.9 & 90.3 \\
\hline $\begin{array}{l}\text { The workbook would help older adults } \\
\text { talk about driving concerns with their } \\
\text { families. }\end{array}$ & 93.7 & 90.9 & 96.7 & 93.9 & 93.5 \\
\hline
\end{tabular}




\begin{tabular}{|l|r|r|r|r|r|}
\hline $\begin{array}{l}\text { Overall, I would rate the usefulness of } \\
\text { the workbook as: }\end{array}$ & & & & & \\
$\quad$ Extremely Useful & 36.5 & 36.4 & 36.7 & 36.4 & 36.7 \\
Moderately Useful & 47.6 & 42.4 & 53.3 & 48.5 & 46.7 \\
Somewhat Useful & 12.7 & 15.2 & 10.0 & 15.2 & 10.0 \\
Not at all Useful & 3.2 & 6.1 & 0.0 & 0.0 & 6.7 \\
\hline
\end{tabular}

\section{Validation}

The validation portion of the study was designed to assess whether the self-screening instrument accurately identified problems with driving, based on health concerns. Spearman correlations were computed between scores from the instrument, the onroad driving assessment, and the clinical evaluation. The results are shown in Table 5 as a function of responses overall, and by sex and age. The first row in Table 5 shows the correlations between the instrument and on-road driving assessment. Overall, subjects' scores on the self-screening instrument were significantly correlated with driving performance measured on the road; that is, those drivers who had a greater number of health concerns as identified by the instrument also tended to have poorer observed driving performance. Significant correlations between instrument and on-road driving scores were also found for the subgroup of drivers age 75 and older. Scores from the instrument and on-road assessment were not significantly correlated for other subgroups.

\begin{tabular}{|c|c|c|c|c|c|}
\hline \multicolumn{6}{|c|}{$\begin{array}{c}\text { Table 5: Correlations Between Self-Screening Instrument-Identified Health } \\
\text { Concerns, On-Road Driving Performance, and Clinical Evaluation }\end{array}$} \\
\hline $\begin{array}{c}\text { Instrument versus On- } \\
\text { Road Driving }\end{array}$ & $-.26^{*}$ & -.34 & -.22 & -.02 & $-.44^{\#}$ \\
\hline $\begin{array}{c}\text { Instrument versus Clinical } \\
\text { Evaluation }\end{array}$ & $.26^{*}$ & .30 & $.35^{\star}$ & -.07 & $.54^{\#}$ \\
\hline $\begin{array}{c}\text { Clinical Evaluation versus } \\
\text { On-Road Driving }\end{array}$ & $-.55^{\#}$ & $-.62^{\#}$ & $-.59^{\#}$ & -.33 & $-.68^{\#}$ \\
\hline
\end{tabular}

${ }^{\#}$ Significant at the $\underline{p}<.01$ level. * Significant at the $\underline{p}<.05$ level.

The second row in Table 5 shows the correlations between the self-screening instrument and the clinical evaluation. Overall, subjects' scores on the instrument were significantly correlated with the clinical evaluation performed by a certified driving rehabilitation specialist. That is, drivers who had a greater number of health concerns as identified by the instrument also tended to have greater deficits in driving-related abilities, as identified by the occupational therapist during the clinical evaluation. Statistically significant correlations between instrument and clinical evaluation were also found for women and drivers age 75 and older. No other correlations were significant.

The final row of Table 5 shows the correlations between the clinical evaluation and the on-road driving assessment (noting that for each subject, the clinical evaluation and onroad driving assessment were administered by separate specialists). Overall, subjects'

\footnotetext{
${ }^{1}$ Correlations involving the on-road driving test are negative because higher scores on the test indicate better performance while higher scores on the other two measures indicates poorer performance or health.
} 
scores on the clinical evaluation were significantly correlated with on-road driving performance. Drivers with greater deficits in driving-related abilities, as identified in the clinical evaluation, also tended to exhibit poorer observed driving performance. A statistically significant correlation between the clinical evaluation and on-road driving assessment was also found for all categories except people ages 65-74.

\section{DISCUSSION}

The objective of this project was to create a valid, easy-to-use self-screening instrument that would provide older drivers with individualized information to help them make better decisions about driving. The project was intended to improve upon existing selfscreening instruments by focusing on the health concerns resulting from medical conditions or medications used to treat them, rather than on the medical conditions or medications themselves, allowing for a much more comprehensive self-screening than has been possible previously. In addition, by linking the severity of health concerns to their effects on critical driving skills, the instrument provided five types of individualized feedback for drivers: general awareness of how certain health concerns can affect driving; self-awareness about individual health concerns and the driving skills that may be declining; individualized recommendations for behavioral changes to maintain safe driving; individualized recommendations for further evaluation; and individualized recommendations for vehicle modifications to maintain safe driving.

In addition to developing the SAFER Driving: Enhanced Driving Decisions Workbook, the study had two primary objectives. The first objective was to determine if the selfscreening instrument increased general knowledge and self-awareness and was perceived as useful. Feedback from subjects immediately following completion of the instrument showed positive results. More than three-fourths of the subjects indicated that the instrument made them more aware of how changes can affect driving and more than $90 \%$ thought the instrument information was useful as a reminder of things they already knew. The instrument's effect on self-awareness was also positive. More than one-third of subjects (38\%) discovered a deficit in themselves of which they were previously unaware. This is a surprisingly high percentage given that all subjects knew they were being recruited for a study in which driving would be evaluated, most were healthy volunteers who were not expected to be experiencing major declines in abilities, and among those experiencing any declines presumably only a subset would be expected to be unaware of the declines. Large percentages of subjects indicated plans to engage in behaviors to maintain safe driving with $42 \%$ planning to change the way they drove, $33 \%$ planning to take a driving refresher course, and $53 \%$ planning to talk with a doctor. Few subjects, however, reported intentions to modify their vehicles even though they received specific feedback on this topic. This may have been because relatively few health concerns can be compensated for through vehicle modifications. For example, specialized mirrors may help with some vision-related concerns (e.g., reduced visual acuity, increased sensitivity to glare) and psychomotor concerns (e.g., upper body stiffness or weakness) but most cognitive impairments are not amenable to such modifications. Subjects may also have been reluctant to consider vehicle modifications because they may have perceived them to be for people with "disabilities" rather than for people aging normally. Further research is clearly needed on the issue of vehicle modifications. 
Subjects found the instrument to be very useful: More than three-fourths would use it again in the future; more than $90 \%$ would recommend it to older family members and friends; and $94 \%$ thought the instrument would serve as a useful way to discuss driving concerns with family members. This latter finding is important because previous research has shown that the topic of older parent driving safety is a difficult topic to discuss in families (see e.g., Beverly Foundation, 2007; Eby, Molnar, Kostyniuk, \& Shope, 1999). Thus, the SAFER Driving: Enhanced Driving Decisions Workbook could serve as a useful tool to help older drivers and families discuss the emotional topic of transitioning from driving to alternative transportation options.

The second objective of the evaluation/validation study was to determine how well scores on the self-screening instrument correlated with actual driving performance and clinical evaluation. A positive, statistically significant correlation was found between scores on the instrument and on-road driving performance. It should be noted that the overall correlation, though significant, was modest, indicating that the self-screening tool was congruent, although not perfectly so, with on-road driving performance. It would be expected that these correlations would be higher if a larger subject sample was used. When various sub-groups of the participant population were analyzed, statistically significant, positive correlations between the instrument and on-road driving assessment were found for drivers age 75 and older. No statistically significant correlations were found between the instrument and on-road driving assessment for other subgroups.

A positive, statistically significant correlation was found between the instrument and the clinical evaluation. As with the comparison with on-road driving, the overall correlation, was modest. However, despite the relatively small sample size it is encouraging that the correlation was in the right direction and significant. When various subgroups of the participant population were analyzed, significant positive correlations between instrument and clinical evaluation scores were found for both women and drivers age 75 and older. No statistically significant correlations were found between the instrument and clinical evaluation for men or drivers ages 65-74. Further investigation is needed to understand these differences by sex and age.

The lack of correlation for women (instrument versus on-road driving), men (instrument versus on-road driving and clinical evaluation) and drivers in the 65- to 74-year-old age group was not surprising. The principal investigators have found similar results in previous work validating the original Driving Decisions Workbook (Eby, Molnar, Shope, Vivoda, \& Fordyce, 2003). In an effort to further understand these outcomes, the project team calculated correlations between the clinical evaluation and the on-road driving assessment. These results showed statistically significant correlations for women and men, indicating the lack of sex differences we observed in our study may be due to some feature of the self-screen instrument. On the other hand, no significant correlation was found for drivers ages 65-74, indicating poor agreement between clinical evaluation and on-road driving for those ages 65-74 years. Thus, it appears unlikely that the lack of correlation for this age group between the self-screening instrument and other measures is simply due to limitations in the instrument. Whether these nonsignificant correlations result from an artifact of the subject population or some other bias needs to be explored in future research. 
Collectively, the results from the evaluation/validation study suggest that the SAFER Driving: Enhanced Driving Decisions Workbook may be a useful and valid selfscreening instrument for older adult drivers, particularly those age 75 and older. It should be noted that the SAFER Driving instrument is intended as a screening tool to determine gross impairment (Staplin et al., 1999) rather than fitness-to-drive. Fitness to drive and recommendations on licensing actions should be determined through in-depth professional assessment. The SAFER Driving instrument does, however, provide recommendations for seeking professional assessment where appropriate.

In conclusion, the SAFER Driving: Enhanced Driving Decisions Workbook appears to be a useful and valid self-screening instrument for drivers age 75 and older. The results did not support validation for the 65-74 age group. The study did have some limitations. The study sample was not representative of the general population of older adult drivers. Study participants were generally White and highly educated. This demographic may have bias judgments of the tool's usefulness in the positive direction. It is important that the research be replicated with a more representative sample of older drivers, particularly with respect to race and education. In addition, the sample was largely a self-selected group of volunteers, a characteristic of most older-adult research that is difficult to overcome but one that makes generalization difficult. The usefulness and effectiveness of the instrument was assessed through self-report, with subjects asked about their intentions to engage in behaviors at a future time. It is unknown if, in fact, people will actually follow through on their reported intentions for behavioral change. Further research that objectively assesses whether or not people change their driving, take a driving refresher course, or see their doctor, would be a valuable next step in determining the behavioral and safety outcomes associated with self screening. 


\section{REFERENCES}

AAA Foundation for Traffic Safety. (1994). Driver 55 Plus: Check Your Own Performance. Washington, DC: AAA Foundation for Traffic Safety.

American Association for Retired Persons. (1992). Older Driver Skill Assessment and Resource Guide. Washington, DC: American Association for Retired Persons.

Beverly Foundation. (2007). Transitions to Transportation Options: How They Affect Older Adults. Pasadena, CA: Beverly Foundation.

Dulisse, B. (1997). Older drivers and risk to other road users. Accident Analysis \& Prevention, 29, 573-582.

Eby, D.W. (1995). The convicted drunk driver in Michigan: A profile of offenders. UMTRI Research Review, 25(5), 1-11.

Eby, D.W., Molnar, J.L., Kostyniuk, L.P., \& Shope, J.T. (1999). The perceived role of the family in older driver reduction and cessation of driving. In $43^{\text {rd }}$ Annual Proceedings: Association for the Advancement of Automotive Medicine (pp. 458460). Des Plaines, IL: AAAM.

Eby, D.W., Molnar, L.J., Shope, J.T., Vivoda, J.M., \& Fordyce, T.A. (2003). Improving older driver knowledge and awareness through self-assessment: The Driving Decisions Workbook. Journal of Safety Research, 34, 371-381.

Eby, D.W., Trombley, D., Molnar, L.J., \& Shope, J.T. (1998). The Assessment of Older Driver's Capabilities: A Review of the Literature (Report No. UMTRI-98-24). Ann Arbor: University of Michigan Transportation Research Institute.

Evans, L. (1991). Traffic Safety and the Driver. New York, NY: Van Nostrand Reinhold.

Gallo, J.J., Rebok, G.W., \& Lesiker, S.E. (1999). The driving habits of adults aged 60 years and older. Journal of the American Geriatrics Society, 47, 335-341.

Hakamies-Blomqvist, L. (1994). Aging and fatal accidents in male and female drivers. Journal of Gerontology: Social Sciences, 49, S286-S290.

Hakamies-Blomqvist, L. (2004). Safety of older persons in traffic. In Transportation in an Aging Society: A Decade of Experience (pp. 22-35). Washington, DC: Transportation Research Board..

Hauer, E. (1988). The safety of older persons at intersections. In Special Report 218: Transportation in an Aging Society: Improving Mobility and Safety for Older Persons, Volume 2. Washington, DC: Transportation Research Board.

Kostyniuk, L.P., Shope, J.T., \& Molnar, L.J. (2000). Reduction and Cessation of Driving among Older Drivers in Michigan: Final Report (Report No. UMTRI-2000-06). Ann Arbor, MI: University of Michigan Transportation Research Institute. 
Massie, D.L. \& Campbell, K.L. (1993). Analysis of Accident Rates by Age, Gender, and Time of Day Based on the 1990 Nationwide Personal Transportation Survey (Report No. UMTRI-93-7). Ann Arbor, MI: University of Michigan Transportation Research Institute.

Maycock, G. (1997). The Safety of Older Car Users in the European Union. Basingstoke, UK: Foundation for Road Safety Research.

Molnar, L.J., Eby, D.W., \& Miller, L.L. (2003). Promising Approaches to Enhancing Elderly Mobility (Report No. UMTRI-2003-21). Ann Arbor, MI: University of Michigan Transportation Research Institute.

Staplin, L., Gish, K.W., Decina, L.E., Lococo, K.H., \& McKnight, A.S. (1998). Intersection Negotiation Problems of Older Drivers, Volume I: Final Technical Report (Contract No. DTNH22-93-C-05237). Washington, DC: U.S. Department of Transportation.

Staplin, L. \& Lococo, K. (2003). Model Driver Screening and Evaluation Program: Guidelines for Motor Vehicle Administrators (DOT HS 809-581). Washington, DC: U.S. Department of Transportation.

Staplin, L., Lococo, K.H., Stewart, J. \& Decina, L.E. (1999). Safe Mobility for Older People Notebook (DOT HS-808-853). Washington, DC: U.S. Department of Transportation.

U.S. Census Bureau. (2006). Population Estimates. Retrieved December 12, 2006, from http://www.census.gov/popest/estimates.php.

U.S. Department of Commerce. (2001). An Aging World: 2001. Washington, DC: U.S. Department of Commerce, Bureau of the Census.

Wilkinson \& Moskowitz, (2001). Polypharmacy and older drivers-- Literature Review. Unpublished Task Order Report for Contract DTNH22-98-D-55079. 

DOT HS 811 046A

October 2008 